\title{
Near-Death Experiences and Kundalini Awakening: Exploring the Link
}

\author{
Yvonne Kason, M.D., C.C.F.P., M.Ed., F.C.F.P. \\ University of Toronto
}

ABSTRACT: This article explores the historical and research evidence that the awakening of latent spiritual energy is the biopsychospiritual basis of near-death experiences (NDEs). This spiritual energy is known in various sacred traditions as Holy Spirit, Vital Winds, chi, dumo fire, mana, and, in the yogic tradition, kundalini. I outline the modern kundalini hypothesis, as first proposed by Gopi Krishna; how this hypothesis can account for the physical symptoms and psychospiritual transformation associated with NDEs; and preliminary evidence from my own NDE and from research underway through the Kundalini Research Network.

On March 27, 1979, I had a most extraordinary experience, which prompted me to research spiritual and paranormal states of consciousness and which has, over the years, led me to the conclusion that kundalini awakening is the mechanism responsible for the phenomena currently known as near-death experiences (NDEs). On that day, I was a young medical doctor, a medical resident, completing my specialty training in family medicine at the University of Toronto. I was assigned that month to work at a remote northern Canadian community, Sioux Lookout, and that day I had been designated by the supervising staff physicians to accompany a critically ill Native Indian woman on a

Yvonne Kason, M.D., C.C.F.P., M.Ed., F.C.F.P., is Assistant Professor of Family Medicine at the University of Toronto Faculty of Medicine, Coordinator of the Kundalini Research Network, and Director of the Spiritual Emergency Research and Referral Clinic in Toronto, where she practices family medicine and medical psychotherapy. Reprint requests should be addressed to Dr. Kason at the Leaside Health Centre, 795 Eglinton Avenue East, Toronto, Ontario M4G 4E4, Canada. 
medical evacuation from our small hospital to a larger hospital in Winnipeg. This medical evacuation took place by small aircraft.

The plane took off in sub-zero weather, and flew into a bad snowstorm. About one hour underway, our plane developed mechanical problems when the air filters of the twin-engine aircraft froze over. Our plane crash-landed onto the surface of a semi-frozen lake, and sank through the ice into about 200 feet of water. I managed to escape from the sinking aircraft, along with the pilot and the nurse. I swam about 100 yards, in icy water with a strong current, to the nearest land, an island.

Once on the shore, I had to wait, soaking wet, in sub-zero weathertechnically a blizzard-until I was rescued. I was a near-drowning victim, with lake water in my lungs, and profoundly hypothermic, nearly frozen, with a body temperature below the bottom reading on the local hospital's thermometer. Fortunately I was rescued and rushed to a local hospital by two selfless heroes. In fact, the story of this crash and rescue was written up in Reader's Digest magazine as a "Drama in Real Life" (Waller, 1981).

This accident had another facet, however, not recorded in Reader's Digest, which had the most profound impact on my life. I experienced a paranormal experience of consciousness that began as the plane was crashing, continued as my body became progressively more hypothermic as I swam to shore, and then continued as I waited on shore for our rescue, huddled against the icy wind, wet and gradually freezing to death. When I first realized that the plane was crashing, my initial reaction was to feel a wave of intense fear. "Oh God, I am going to die!" was my first thought. I was overwhelmed with panic and fear.

Suddenly, as if poured into my consciousness by another force, I started hearing verses from the Bible in my mind, verses that were reassuring and comforting, verses that I could not consciously quote verbatim. The fear and panic were displaced by an intense sense of peace and calm. I suddenly felt that God was there, and that everything would be all right. I was no longer afraid.

After the plane crash-landed onto the ice, I tried to pull the stretcherbound patient out of the plane, but was unable to do so before the plane sank. As the plane and patient disappeared into the dark icy water, I heard a voice in my head clearly state, "Swim to shore." I looked to shore, and saw that it was quite far away.

Dark open water lay between me and the shore. Turning away from shore was ice on the surface of the water. My intellect argued with the inner voice. I remembered some of the life-guarding courses I had 
taken as a teenager. "Do not attempt to swim to shore in the event of a boating accident," I had been taught. "Stay by the boat. Shore is farther than it seems; you will drown while swimming to shore."

So, I ignored my inner voice for a while, as I repeatedly strived to climb onto the very thin ice farther away from shore. Finally, as I become colder and colder, and progressively more exhausted from my futile attempts to climb on the ice, my inner voice again loudly repeated, "Swim to shore." Finally, I obeyed my higher directive.

As I was swimming the 100 yards or so to shore, I heard a wind-like noise, and I felt as if my consciousness suddenly lifted up out of my body. It seemed as if my point of perception was now 15 feet or so above my body, and that I was looking down, accurately perceiving what was happening to my body below. The feeling of peace and calm that had begun earlier in the crash was still with me.

I detachedly watched my body struggling to swim to shore through the icy water and strong current. I saw it go under twice, exhausted. I knew it was my body, and I somehow intuitively knew that I was dying. However, I felt totally unafraid. Somehow the peaceful state of mind that had taken me over also gave me the intuitive knowledge that there is nothing to fear in death. I felt the most ecstatic, blissful, wonderful emotion I have ever experienced. I felt enveloped, protected, embraced by a loving force. I was surrounded by light. I sensed that I was in the presence of and being lovingly embraced by the loving intelligent power behind the universe-what I call God.

I watched the event happening to my physical body below with detachment and complete trust and surrender to the divine. I knew that the outcome was somehow already predetermined by the loving intelligence that was embracing me and uplifting my spirit. I was totally unafraid to die. I knew there was nothing to fear in death. I watched in anticipation to see the outcome of the worldly events below.

After I was rescued, my near-frozen body was taken to Kenora Hospital. My consciousness seemed to be floating above my body, and at times piercing through to speak through my body. At one point, I could feel my consciousness starting to drift farther away from my body. The hospital staff were inexperienced in treating hypothermia, and they did not seem to realize the critical condition I was in.

Suddenly my body spoke the words, "Boy, could I use a hot bath." The nurses responded by saying to each other, "Maybe that would help them; let's take them down to the physiotherapy department and put them in the hot whirlpool baths." It turns out that submerging us in 
hot water was the best medical thing for them to do at that time to treat the hypothermia. However, at the time that I spoke those words, I did not consciously know that fact!

When my body was placed into the hot whirlpool bath, I suddenly felt my consciousness re-enter my body. It felt as if I was forcefully sucked down from a higher, more expanded space, through the top of my head, into my body. I felt myself actively sucked back into my body, in a way I imagine a genie feels when being forcibly sucked into the confines of its bottle. When my consciousness re-entered my body, I abruptly felt my spirit and point of perception were back in my body. I then knew that I was meant to live, and that I had survived the ordeal of the plane crash.

At that time, in 1979, I had no idea how to interpret this experience. Being a traditionally trained Canadian medical doctor, I had never heard of such an experience. I had been exposed to the writing of Elisabeth Kübler-Ross, and had heard vaguely of near-death experiences, but since I had never been dead at any time during this accident, I thought this experience must be something else. In fact, my experience began while I was fully conscious and alert, continued while I was actively swimming to shore, and then continued on as I began to approach death, as my body became progressively more hypothermic. Initially, the only way I could conceptualize this experience was to call it a mystical experience. I therefore began to research mystical experiences of all types, including those labelled as NDEs.

The psychological impact of this mystical experience was very strong. First, it absolutely convinced me of the reality of the loving intelligence behind the universe, which I call God. Second, the experience made me totally lose my fear of death. I became absolutely certain that the spirit lives on after death.

Third, the experience has etched itself into my memory. I can still clearly recall the experience. Even though 15 years have passed, I still feel a strong personal sense of connection with the intelligent power behind the universe. Finally, the experience convinced me that all humans, regardless of race, creed, and religious denomination, have the same personal connection to the power behind the universe. I became convinced that we are all essentially spiritual beings, children of the same one all-loving God.

The mystical experience also seemed to have a transformative effect upon my consciousness. About one month after the plane crash, I had my first clairvoyant experience. Since that time I have had many psychic experiences, a predilection that I did not have prior to the experience. 
Also, I seemed spontaneously to unblock traumatic childhood memories and rapidly heal the associated unresolved psychological conflicts. In my case, after many years of a dysfunctional relationship with my father, after unblocking a particularly traumatic memory from around age five years, I was then able rapidly to work through feelings of anger left over from this childhood incident. I seemed to have new clarity of perception, and was able to see the complexity and truth of the childhood situation more clearly. I also discovered an increased desire and increased ability within myself to forgive my father.

This experience also propelled me professionally, inciting my scientific curiosity to begin to research what is known about various types of mystical and paranormal consciousness experiences. Over the last 14 years, as well as doing an extensive literary review of the topic, I listened to the stories and counseled well over 200 persons in Canada and the United States who have had various types of mystical and paranormal experiences, experiences I now cluster together under the umbrella term of "spiritually transformative experiences." Further, as part of my ongoing research, I have read detailed personal accounts of at least another 200 persons. In response to the need expressed by these persons to have a supportive physician and counselor to talk to after such an experience, I founded and now direct the Spiritual Emergence Research and Referral Clinic in Toronto, Canada.

My research and clinical experience has led me to the conclusion that what is presently termed as near-death experiences is one sub-type of experience within a spectrum of spiritually transformative experiences (STEs). The full range of STEs includes mystical experiences of all types, near-death experiences, psychic awakenings, inspired creativity experiences, spiritual energy experiences, and in some cases transient psychosis with mystical features.

Mystical experiences may take many forms, including: mystical visions of deities, saints, gurus, or spiritual archetypes; bliss episodes, ecstatic experiences of all-encompassing love, joy, or devotion; unitive experiences, a feeling of union with God or the universal intelligence, or sensing the one-ness of all things; expansive episodes, a sense of a dramatically expanded point of perception; spiritual rebirth, a sudden profound spiritual awakening or spiritual conversion; and illumination, a profound insight into the nature of the universe.

Spiritual energy experiences are marked by sensations of energy coursing up through the body and/or spine, inner light sensations, and inner sounds such as ringing, buzzing, or roaring like the wind, and are associated with a paranormal or mystical experience. Spiritual energy experiences are known by various terms in different spiritual 
traditions, including kundalini awakening, shakti, Holy Spirit, Holy Wind, Circulation of Light, dumo fire, Vital Winds, and chi kung.

My own research has led me to the conclusion that the broad range of spiritually transformative experiences may all, in fact, be due to the activation of a latent biological/psychological/spiritual energy mechanism in the body. This mechanism is known and well described in the yogic tradition as kundalini. Kenneth Ring in his book Heading Toward Omega (1984) speculated on kundalini awakening as being the cause of NDEs. Research underway, coordinated through the Kundalini Research Network, an international research collaborative, suggests that persons having all types of spiritually transformative experiences, including NDEs, have symptoms suggestive of kundalini activity.

Gopi Krishna, a contemporary Indian scholar and kundalini researcher, presented a very detailed modern perspective on kundalini and its possible causative role in NDEs and other spiritual experiences. He provided a concise update of the ancient yogic kundalini knowledge in his many books on the modern kundalini hypothesis (Krishna, 1971, 1972a, 1972b, 1974, 1975, 1978a, 1978b, 1978c, 1988). Near-death experiences are caused by a transient kundalini awakening, in his opinion.

Krishna described an ancient yogic practice, perhaps 5000 years old, called kercheri mudra, in which a spiritual aspirant would attempt to induce a mystical state by deliberate partial asphyxiation, an intentional NDE. The aspirant would make fine progressive cuts in the frenulum under the tongue, to enable the tongue to flex farther and farther backwards. In time, the aspirant would eventually be able voluntarily to obstruct the airway with the tongue. In the yogic esoteric tradition, it was believed that at the time when the airway was blocked in this manner, the kundalini energy would sometimes awaken from its dormant center at the base of the spine, and carry a potent stream of life energy or prana to the brain, to protect the brain from hypoxic injury. At the point when the kundalini mechanism drives the potent prana to the brain, the aspirants would experience their goal, a mystical state of consciousness, today called a near-death experience. The kundalini would not always arise with this practice, for reasons unclear then and still unclear now.

\section{The Modern Kundalini Hypothesis}

The modern kundalini hypothesis, as first put forward by Gopi Krishna, provides a "missing link," a plausible theory to account for the biopsychospiritual basis for all types of paranormal and spiritual experiences, including near-death experiences. It is a modified and 
modernized version of the kundalini theories put forward in the ancient yogic texts, the tantras, and the shakti-shastras.

The basic premise underlying the modern kundalini hypothesis is that there exists a yet unidentified life energy present in all living creatures, called prana in the yogic tradition, chi energy in the Orient, and bioenergy, bioplasma, or the life energy in the West. This subtle, intelligent life energy vivifies each human cell, and circulates through the nervous system to the brain, providing psychic fuel and the substance of consciousness for our minds. Under certain conditions, a normally dormant potential mechanism in the body is activated, causing two distinct changes.

First, the body is stimulated to send a stronger, more potent stream of prana and a psychic nutrient, ojas, to the brain via the central nervous system. Second, a previously dormant region in the brain, the brahma randhra, becomes stimulated into activity, leading to the development of an expanded range of conscious perceptions, which are presently considered paranormal or mystical experiences. This twopronged potential mechanism is called kundalini, and its activation is called kundalini awakening.

In the modern kundalini hypothesis, Krishna proposed that with the awakening of the kundalini mechanism, a more potent form of prana or bioenergy streams to the brain via the spinal cord. The human nervous system has this yet unrecognized activity in addition to its normal functions. Certain cells of the body produce prana, perhaps in the mitochondria. Air and food also contain prana. The peripheral nervous system extracts prana from the cells of the body, from the air we breathe, and from the food we have eaten, and transports the prana to the brain via the central nervous system. This prana is used by the brain as psychic fuel.

The sexual organs and the nerves are the two major storehouses or reservoirs for prana in the body. Upon the activation of the kundalini mechanism, the nervous system is stimulated into a higher degree of activity, to extract greater amounts of prana from all the cells of the body, and especially from the reservoirs in the sexual organs and in the nerves.

The sexual organs are said to also be capable of sending subtle essences, or ojas, extracted from and transmuted out of the sexual secretions, upward, via the spinal cord. This ojas is said to act as a tonic and regenerative elixir, nutritive for the evolving brain center. It is postulated that these fine essences normally vivify the seed, if emitted downwards during the sexual act. If the sexual secretion essences are instead transmuted and released upwards as ojas, they provide a concentrated form of psychic fuel with regenerative capabilities for the 
newly activated, transforming brain center. This sublimation of the sexual secretions and their transmutation into psychic fuel is known in the yogic tradition as urdhva-retas, literally translated as upward flow of semen.

Further, it is proposed that upon the awakening of the kundalini mechanism, a previously dormant region of the brain, known in the yogic tradition as the brahma randhra, is "awakened," or stimulated to activity. The exact anatomic location of the brahma randhra is not presently known, but it is said to be centrally located in the brain, just above the rear of the palate. It is thought not to be the pituitary, and probably not the pineal gland.

When properly fueled with the increased amounts of potent prana extracted by the now more highly active nervous system, and nourished with the nutritive ojas, the newly activated brahma randhra region of the brain begins to function, usually in a limited way initially. In time, as the brahma randhra is continuously stimulated, it transforms and develops, resulting in the brain developing new mental faculties, new channels of perception. This change in consciousness is described in various mystical and esoteric traditions as the opening of the third eye/inner eye, the development of the sixth sense, or shedding of the veils of maya.

As this brain center first activates, only transient flashes or brief episodes of new expanded mental perceptions may occur. Often, the paranormal perceptions may initially occur only during meditation, prayer, or during times of deep absorption and concentration. With time, if the kundalini remains active, and the brahma randhra continues to be stimulated and fed with increased amounts of healthy potent prana, the brain becomes gradually capable of more frequently perceiving subtle energies and dimensions normally beyond perception by the human mind. A condition is often reached, in time, in which a person with an awakened kundalini regularly has mystical visions and paranormal experiences during meditation. This episodic and variable pattern of experiences of expanded states of consciousness may continue for the rest of the person's life.

In extremely rare cases, after many years of stimulation by the kundalini mechanism, the brahma randhra region of the brain may become completely activated and transformed to a level of stabilized, ongoing, full functioning, while the person is able, at the same time, to maintain concentration on external realities also. Such a person would exist in a perennial state of mystical ecstasy, with the third eye always functioning. They would live in higher consciousness, in constant mental contact with the subtle energies behind the universe, 
not just during meditation, but also while participating in external worldly activities.

This state is called the sahaja-samadhi, the sahaja state, or the turija state in the yogic tradition; Buddha consciousness, Christ consciousness, or perennial enlightenment in other traditions. The term sahaja means "co-emergent," describing the coexistence of two states of consciousness, mystical ecstasy and normal worldly mental functioning. Richard Maurice Bucke (1901), the Canadian psychiatrist, called this "perennial cosmic consciousness." Ring (1984) called this "omega," after Pierre Teilhard de Chardin. Bucke, Ring, and Krishna all hypothesized perennial cosmic consciousness to be the next evolutionary step for the entire human race.

Upon the activation of the kundalini mechanism, the entire body and all the bodily organs must adjust to a higher level of activity to meet the higher energy demands of the transforming brain. As the cells become more active and increase their production of prana, and the nervous system becomes more active in its transport of prana to the brain, energy sensations may be perceived. Persons describe feelings of their body tingling with energy, or feelings of energy flowing up their arms or legs, and frequent sensations of energy streaming up their spinal column to the brain. Unusual sensations may be felt at what are called chakra points in the yogic tradition.

Chakra points are said to be energy centers, associated with the body's major nerve plexuses as well as with the subtle/etheric energy body, perhaps acting as communication points between the nerves and the etheric body. The exact number and locations of the chakras are disputed among various traditions. In the yogic tradition there are said to be seven chakras. Five chakras are said to lie along the spine, the lowest at the base of the spine, the second a few inches higher, the third at the solar plexus, the fourth at the heart region, and the fifth at the throat. The sixth is at the third eye region, by the forehead between the eyebrows, and the seventh is just below the crown or top of the head.

After a kundalini awakening, various energy sensations may intermittently be felt at these chakra points. Energy vortices may be perceived at the chakra points, as if the pranic and bodily energies swirl and communicate at these centers. Persons may also perceive pranic energy flows throughout their body. They may perceive luminescent prana circulating about their body organs and flowing upwards through their nervous system, or colors and subtle glistening energies surrounding the body in an aura.

Following a kundalini awakening unusual sensations may frequently be felt in several of the bodily organs. Most marked sensations 
may be felt in the sexual organs, as prana is extracted from these potent prana reservoirs, and as ojas is ejected upwards. An upward sucking sensation from the genital area may be perceived, as well as unusual fluctuations in sexual energy and sexual desire. Spontaneous orgasms may occur, as well as orgasms without outward release of ejaculate. The increased activity of the other bodily organs may be noticed especially in the digestive system, with an increase in appetite and an increase in the frequency of bowel movements, and in the heart's activity, with an increase in pulse rate.

\section{The Kundalini Hypothesis and Near-Death Experiences}

Most near-death experiences follow certain patterns. This has been well documented by the research of Raymond Moody (1975; Moody and Perry, 1988), Ring (1984), Melvin Morse (Morse and Perry, 1990), and Tom Harpur (1991), as well as by my own clinical experience and research. There are definite similarities and patterns in the experiences persons have described when "coming back" from a near-death experience.

Commonly reported features of an NDE, listed in the order that they generally tend to occur, include hearing what was said around the body, strong feelings of peace, unusual inner noises, floating out of the body and clearly seeing the body and surroundings below, a dark tunnel, meeting spirits, white light experiences, a life review, a life border, and abrupt return to the body. Common after-effects include conviction of the reality of the experience; transformational impact, including new spiritual insights, stronger spiritual convictions, and an increased occurrence of psychic phenomena; new views of death, including loss of fear of death; independent corroboration of events witnessed while out of the body; and ineffability of the experience.

According to Moody's near-death research, persons rarely have all of these experiences but commonly persons will have around eight of the 15 features. The order in which these experiences occur, however, seems fairly constant.

The progression of typical symptoms in a near-death experience can be understood in light of the chakras and kundalini activation. It is held by several Eastern esoteric traditions that at the time of death, the kundalini energy awakens, rises to the crown chakra, and enables the spirit to leave the body via the crown of the head. Some esoteric writers even speculated that the silver cord, which is said to attach the spirit to the body, is really a manifestation of the kundalini. 
Considering this perspective, the progression of symptoms common during a near-death experience can be explained related to the progression of the chakras as the kundalini is raising. Typically, one of the first sensations during an NDE is a feeling of great peace and calm, that there is nothing to fear, that all is right with the universe. These emotions and feelings are typical of those experienced when the kundalini raises to the heart chakra, a so-called heart opening. According to the kundalini hypothesis of NDEs, these symptoms appear first, because after the kundalini awakens, it first rises to the heart chakra, a so-called partial kundalini awakening.

As the NDE continues, the kundalini rises farther up the body. When the kundalini reaches the third eye or sixth chakra, a psychic awakening occurs, and an out-of-body experience results. This out-of-body experience, floating above the physical body and accurately viewing what is happening below, almost invariably occurs after the feeling of peace begins in an NDE.

If the NDE continues, the kundalini continues to rise even higher, and reaches the crown chakra. It is upon reaching the crown chakra that the individual experiences a mystical experience, and experience of the light. The classical symptoms of the kundalini reaching the crown chakra are light, expansion of consciousness, and a mystical experience with or without a mystical vision. This is typical of the experiences NDErs go on to have, such as the dark tunnel with light at the end; feeling merged into the light; having mystical visions of saints, gurus, and deities; visions of departed loved ones; and receiving spiritual life messages. Classically, kundalini awakening is also associated with the experience of an inner sound, another symptom frequently described by NDErs.

According to the kundalini hypothesis, once the kundalini mechanism is initially activated or awakened, especially if raised to the crown or seventh chakra, it rarely turns off completely. The kundalini returns to the root chakra after the NDE, but the mechanism would then continue to be active, but to a small degree. This is in keeping with Morse's research observations described in his book Transformed by the Light (Morse and Perry, 1992). He documented that those NDErs who saw the light were the ones who were spiritually transformed afterwards, with a loss of the fear of death, an increase in spiritual focus, and an increase in psychic experiences after the NDE. Those NDErs who never experienced the white light did not experience such a spiritual transformation.

According to the modern kundalini hypothesis, those NDErs whose kundalini rose to the crown chakra are those who saw the light. These 
experiencers therefore never had their kundalini mechanism completely shut off afterward. The NDE would result from a sudden blast of high kundalini stimulation of the brain, with the years afterwards having a more subtle, gentle kundalini activity continuing on, making their minds more open to mystical and psychic experiences.

Further, the low level of kundalini activity after the NDE may increase over time, eventually becoming perceptible to the NDEr as ongoing or recurrent low level kundalini symptoms, such as ongoing inner sounds, intermittent light perceptions, or intermittent rushes of energy up the body and/or spine. This ongoing kundalini activity may also be noticed by its effect of gradual stimulation of the brahma randhra brain center. This stimulation would be perceived as the gradual development and increase in frequency of psychic experiences, recurrent mystical experiences, or more rarely as an increase or development of inspired creative gifts.

According to the modern kundalini hypothesis, most NDErs who experienced the light should notice some degree of gradually increasing, ongoing kundalini transformation following their NDE. Those NDErs who further stimulate their kundalini through yoga, meditation, intense prayer, intense concentration, or other spiritual practices are the most likely to notice a perceptible increase in kundalini symptoms over time, with the development of recurrent psychic and/or mystical experiences.

\section{NDE-Like Experiences}

NDEs appear to be a very broad spectrum of experiences related in time to being close to death. I use the term "NDE-like experiences" to describe the mystical and out-of-body experiences reported by persons who have not been physically dead or unconsciousness and then resuscitated. Persons who have came close to becoming unconscious or who had a very brief brush with death will sometimes report an experience that includes only two or three of the early NDE features listed above, typically being overwhelmed with a feeling of peace, and then an outof-body experience without an experience of light. This experience ends abruptly when the person is rescued or resuscitated.

NDE-like experiences have also been repeatedly reported by persons who thought they were going to die, but who never actually became unconscious or clinically dead. These persons, however, psychologically faced death. This has been well documented on the battlefields of war, with many soldiers in the line of fire, believing themselves about to be 
killed, reporting out-of-body experiences, seeing their life flash before their eyes, feeling the presence of loving spirits protecting them, and experiencing many of the other classic features of NDEs.

Close-call automobile accidents are another frequent psychological trigger of NDE-like experiences. Many people anecdotally will describe seeing their life flash before their eyes, or transiently flipping out of their body in very frightening or life-threatening situations. I view these experiences as being somewhere in the spectrum of NDE-like experiences of consciousness, less dramatic than a full blown NDE, but clearly related. They may be due to a psychological triggering of a partial kundalini awakening.

The final group of NDE-like experiences is the mystical experiences had by persons shortly before they actually die. These are called "death-bed visions" by some researchers. As a medical doctor, I often work with elderly patients, hospitalized with illnesses that will ultimately cause their death. Repeatedly I have heard elderly persons tell me that they had a mystical "vision" or a "dream." Sometimes they report seeing a dark tunnel, with a brilliant white light at the other end. Often they will describe seeing the spirits of deceased loved ones coming to greet them. They may say they saw beautiful luminous spirits of their departed spouse, parents, siblings, or even close friends. Sometimes they will report seeing visions of one of their religious prophets welcoming them, such as Christ, or Mary.

These persons close to death often know inwardly that they will be dying shortly, and they interpret their NDE-like experience as being a sign of their impending death. After the NDE-like experience, the terminal person is usually changed, they become much calmer, much more at peace. They will often try to use their remaining time to tell their family members that they love them, and not to grieve for them. They may reassure their remaining relatives that death is welcome to them, and that they are not afraid to die. Persons who have had this type of prior-to-death NDE usually die a very peaceful and serene death. I think that death-bed visions may also be related to kundalini activation in preparation for death.

\section{Conclusions}

Current scientific understanding can not explain the phenomena of near-death experiences, or any of the other types of spiritually transformative experiences. Research is needed to test the modern kundalini hypothesis, and to examine the relationship between near-death experiences and the development of symptoms of kundalini activity. 
This research has begun: I am presently chairing such a project, coordinated through the Kundalini Research Network, an international, nonsectarian research collaborative. In a multi-center study, detailed case histories are being collected from persons around the world who are having various types of STEs, including NDEs.

Although this research is presently underway, some preliminary data, available after the completion of the pilot study in 1991, support the relationship between kundalini and NDEs and other STEs. All the NDErs in the pilot study reported the development of recurrent or ongoing symptoms of kundalini activity. Further, all the NDErs reported the development over time of ongoing or recurrent psychic experiences, as well as recurrent mystical experiences. The sample size in this pilot study was very small, so no conclusions can be reached. However, this preliminary evidence strongly suggests that further research should be done to examine this hypothesis.

My research and personal and clinical experiences have brought me to the conclusion that the entire spectrum of NDEs and NDE-like experiences may all be related to the triggering of the kundalini mechanism, at a time when the body physically or psychologically faces death. Since the kundalini mechanism may also be activated at other times, spontaneously or especially during meditation or intense prayer, this can explain why people also report NDE-like experiences in completely non-life-threatening situations.

In the case of my own out-of-body and mystical experience in the plane crash, I now call it an NDE with confidence. My NDE began as I psychologically faced death, and continued on until I physically faced death, ending when my body was rescued and out of physical danger. The modern kundalini hypothesis provides a plausible explanation for my symptoms and experiences, both during the NDE and for the 14 years afterwards.

In conclusion, I think that NDEs form one subtype of experience within the spectrum of spiritually transformative experiences occurring to persons in the world today. The modern kundalini hypothesis provides a plausible scientific theory, a missing link, providing a model to understand the biological basis of NDEs and all mystical experiences. As such, the modern kundalini hypothesis warrants extensive research.

\section{References}

Bucke, R.M. (1901). Cosmic consciousness. New York, NY: Dutton. Harpur, T. (1991). Life after death. Toronto, Ontario: McClelland and Stewart. Krishna, G. (1971). Kundalini- Evolutionary energy in man. Berkeley, CA: Shambala. 
Krishna, G. (1972a). The biological basis of religion and genius. New York, NY: Harper and Row.

Krishna, G. (1972b). The secret of yoga. New York, NY: Harper and Row.

Krishna, G. (1974). Higher consciousness: The evolutionary thrust of kundalini. New York, NY: Julian Press.

Krishna, G. (1975). The awakening of kundalini. New York, NY: Dutton.

Krishna, G. (1978a). The dawn of a new science. New Delhi, India: Kundalini Research and Publication Trust.

Krishna, G. (1978b). Secrets of kundalini in Panchastavi New Delhi, India: Kundalini Research and Publication Trust.

Krishna, G. (1978c). Yoga: A vision of its future. New Delhi, India: Kundalini Research and Publication Trust.

Krishna, G. (1988). Kundalini for the New Age: Selected writings by Gopi Krishna. (G. Kieffer, Ed.). New York, NY: Bantam.

Moody, R.A., Jr. (1975). Life after life. Covington, GA: Mockingbird.

Moody, R.A., Jr., and Perry, P. (1988). The light beyond. New York, NY: Bantam.

Morse, M., and Perry, P. (1990). Closer to the light: Learning from the near-death experiences of children. New York, NY: Villard.

Morse, M., and Perry, P. (1992). Transformed by the light: The powerful effect of neardeath experiences on people's lives. New York, NY: Villard.

Ring, K. (1984). Heading toward omega: In search of the meaning of the near-death experience. New York, NY: William Morrow.

Waller, A. (1981, February). Down in Devil's Gap. Reader's Digest, pp. 25-30. 